

\section{Artigo Especial}

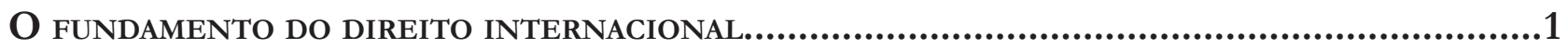
Alfred Verdross

\section{Proteção Internacional dos Direitos Humanos}

INDIGENOUS RIGHTS MOVEMENT: IS THE SAME NEEDED TO PREVENT CONTINUED HUMAN RIGHTS VIOLATIONS OF THE MENTALLY ILL

Liesel LeCates

O Discurso DAS DROGAS CONSTRUído PELO DIREITO INTERNACIONAL

Camila Soares Lippi

O ESTADO DEMOCRÁTICO DE DIREITO LAICO E A "NEUTRALIDADE" ANTE A INTOLERÂNCIA RELIGIOSA

Antonio Baptista Gonçalves

UM DiREITO SEM ESTADO? DiREITOS humanos E A FORMAÇÃo DE UM NOVO QUADRo NORMATIVO GLOBAL .87

Anderson Vichinkeski Teixeira e Rafael Köche

\section{Direito Humanitário}

The U.N. Standard Minimum Rules for the Treatment of Prisoners and North Korea: How North Korea is Violating these Rules with its Operation of the Yodok Concentration CAMP.

Tom Theodore Papain

U.S. Institutionalized Torture with Impunity: Examining Rape and Sexual Abuse in Custody Through the ICTY JurisprudenCE. 126 Allison Rogne 
Abduction, Torture, Interrogation: An Argument Against Extraordinary RendiTION

Kaitlyn E. Tucker

United States and European Union approaches to the death penalty: America SHOULD CONSIDER A NEW PERSPECTIVE 155 Katie R Hill

Tudo DE NOVO NO FRONT: MONUSCO, UMA NOVA ERA NAS PEACEKEEPING OPERATIONS? .169 Priscila Fett

A ADMINISTRAÇÃo DE TERRITÓRIOS OCUPADOS: INDETERMINAÇÃO DAS NORMAS DE DIREITO INTERNACIONAL HUMANITÁRIO?. 184 João Henrique Ribeiro Roriz, Fabia Fernandes Carvalho Veçoso e Lucas da Silva Tasquetto

THE (IN)APPLICABILITY OF THE STATUTE OF REFUGEES TO ENVIRONMENTALLY DISPLACED PERSONS 197 Maria Cláudia da Silva Antunes de Souza e Lucas de Melo Prado

\section{Sistema Interamericano de Direitos Humanos}

A contribuição da Comissão Interamericana de Direitos Humanos para o acesso À jus-

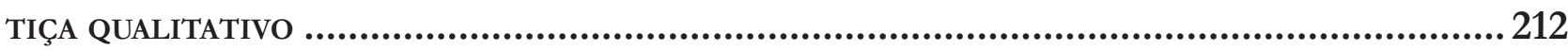
Márcio Antônio de Oliveira Filho, Ana Caroline Portes de Oliveira, Jéssica Galvão Chaves e Warlen Soares Teodoro

A executividade das sentenças da Corte Interamericana de Direitos Humanos no

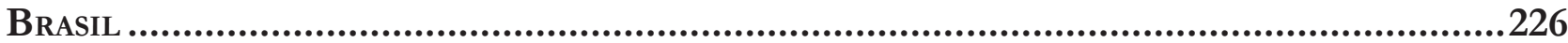

Augusto César Leite de Resende

A efetividade do ativismo jurídico transnacional no Sistema Interamericano de DiREITOS HuMANOS: UMA ANÁLISE A PARTIR DE CASOS CONTRA O BRASIL .................................238 Renata Mantovani de Lima e Lucélia de Sena Alves

O Processo e o Direito Coletivo no Sistema Interamericano de Direitos Humanos: UMA ANÁLISE COM BASE NA JURISPRUDÊNCIA INTERNACIONAL ...........................................250 Laercio Dias Franco Neto e Dafne Fernandez de Bastos 
CORTE INTERAMERICANA DE DIREITOS HUMANOS: OPINIÃo CONSULTIVA 4/84 - A MARGEM DE

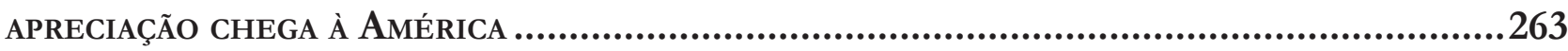

Paloma Morais Corrêa

A "PLENA" LIBERDADE DE EXPRESSÃo E OS DIREITOS HUMANOS: ANÁLISE DA JURISPRUDÊNCIA DA Corte InTeramericana de Direitos Humanos e o Julgamento da ADPF 130 281 Natália Paes Leme Machado

A proteção do meio ambiente no Sistema Interamericano de Direitos Humanos a parTIR DO DIREITO À EDUCAÇÃO.

Augusto César Leite de Resende

Parameters and procedures of the Inter-American System of Human Rights in CHILDREN'S RIGHTS VIOLATION LAWSUITS

Maria Guiomar da Cunha Frota e Pedro Alves Barbosa Neto

Poverty as a Violation of Human Rights: THE CASE OF STREET CHILDREN IN GUATEMALA AND BRAZIL

Paloma Morais Correa

\section{Proteção Internacional dos Direitos Humanos e o Direito Brasileiro}

A LEI N. 11.340/06 E SUAS REPERCuSSõES No CONTRATO INDIVIDUAL DE TRABALHo. Humberto Lima de Lucena Filho e Waldeny Pereira Filho

ORIENTAÇÃo SEXUAL E DISCRIMINAÇão NO AMBIENTE LABORAL

Glaucia Fernanda Oliveira Martins Batalha

NORMAS EDITORIAIS 


\title{
A contribuição da Comissão Interamericana de Direitos Humanos para o acesso à justiça qualitativo $^{1}$
}

\author{
"Access to justice qualitative - The \\ Contribution of the Inter-American \\ Commission on Human Rights"*
}

\author{
Márcio Antônio de Oliveira Filho \\ Ana Caroline Portes de Oliveira \\ Jéssica Galvão Chaves \\ Warlen Soares Teodoro**
}

\section{Resumo}

Pretende-se com este artigo demonstrar a contribuição da Comissão Interamericana de Direitos Humanos para o acesso à justiça de qualidade a partir da preocupação do órgão externada pelo questionário direcionado aos Estados signatários e à sociedade civil e a análise das denúncias de violação aos direitos humanos acolhidas pela Comissão. Percebeu-se que as garantias funcionais dos operadores de justiça afetavam o acesso à justiça de qualidade e, com isso, adveio a necessidade de um tratamento mais adequado e voltado para os problemas atuais, à luz do paradigma democrático e das mudanças ocorridas nos planos interno e internacional. Defendeu-se a existência da quarta onda renovatória, calcada na ideia de inclusão democrática no ensino jurídico e resgate ético do conceito de justiça. O problema atual não é simplesmente medir o acesso dos cidadãos à justiça, propõe-se uma mudança importante de foco: da preocupação das questões metodológicas para as epistemológicas. Concluiu-se que houve, por parte da Comissão, a adoção de uma concepção qualitativa de acesso à justiça e que encontra respaldo nas ponderações levantadas pelos defensores da quarta onda renovatória.

Palavras-chave: Acesso à justiça qualitativo. Quarta onda renovatória. Comissão Interamericana.

* Recebido em 19/07/2013 Aprovado em 31/07/2013.

** Mestrandos em Direito na PUC-MG. Emails: marciooliveirabh@gmail.com; oliveira_ portes@yahoo.com.br; jessica.gchaves@gmail. com; warlen_soares@hotmail.com

\section{Abstract}

The purpose of this article is to demonstrate the contribution of the Inter-access to quality justice. From the concern of the Commission on Human Rights, externalized by questionnaire given to the signatory States and civil society, we analyzed the reports of human rights violations received

1 Trabalho apresentado para a disciplina Jurisdição Internacional dos Direitos Humanos, da grade curricular do mestrado em Direito Processual da Pontifícia Universidade Católica de Minas Gerais. 
by the Commission and identified the factors that led to produce the aforementioned questionnaire. It was noticed that the functional guarantees of justice operators affected access to justice and quality, thus stemmed the need for appropriate treatment and facing the current problems in the light of the democratic paradigm and the changes both internally and internationally. Defended the existence of the fourth wave renewals, based on the idea of democratic inclusion in legal education and ethical redemption of the concept of justice. It was concluded that the current problem is not simply measure citizens' access to justice. We propose a major change of focus: methodological issues of concern to the epistemological. Also concluded that there was, by the Commission, adopting a qualitative conception of access to justice and finds support in the weights raised by advocates of fourth wave renewals.

Keywords: Access to Justice qualitative. Fourth wave renewals. CIDH.

\section{INTRODUÇÃo}

A esperança de uma justiça de qualidade, além de ser um direito humano de importância reconhecida mundialmente, é anseio de todos que procuram o Poder Judiciário para resolver qualquer questão.

O presente artigo objetiva, a partir da preocupação da Comissão Interamericana de Direitos Humanos, externada pelo questionário direcionado aos Estados signatários e à sociedade civil, identificar as situações que violam as garantias funcionais dos operadores de justiça e impedem o acesso à justiça de qualidade.

Percebeu-se a necessidade de um tratamento mais adequado e voltado para os problemas atuais, à luz do paradigma democrático e das mudanças ocorridas nos planos interno e internacional, que afetam o acesso à justiça.

Dessas percepções originaram as seguintes questões: Há um novo olhar sobre essa temática? Qual a importância da Comissão Interamericana de Direitos Humanos para o acesso à justiça? Há uma quarta onda renovatória? Quem pode se qualificar como promotor, defensor público ou juiz? Quem tem acesso às faculdades de direito?

Esses questionamentos foram enfrentados sem diminuir toda a construção erguida pelo Projeto de Flo- rença. Manteve-se o olhar multidisciplinar a fim de buscar uma nova percepção sobre o mesmo fenômeno e identificar soluções desta feita qualitativas.

$\mathrm{O}$ artigo apresenta como ponto de partida a noção de acesso à justiça como direito humano. Explicita os meandros do Projeto de Florença, apresentando os obstáculos e as suas propostas de soluções, além de caracterizar a transição de paradigmas que traduziu a inadequação das propostas. O texto também identifica a ausência de preocupação do aspecto qualitativo do acesso à justiça e adentra nas características norteadoras da quarta onda renovatória, cuja preocupação está voltada ao aspecto qualitativo.

Por fim, analisou-se o questionário elaborado pela Comissão e as denúncias recebidas pelo órgão, de onde se extraiu as contribuições da Comissão Interamericana de Direitos Humanos para a implementação do acesso a justiça de qualidade.

\section{Acesso à justiça e o Projeto de Florença}

\subsection{O acesso à justiça como direito humano}

Os direitos humanos nasceram da necessidade de proteção dos indivíduos contra as arbitrariedades do Poder Estatal e, por essa razão, passaram a orientar as políticas públicas. Atualmente, transcenderam o plano estatal para também orientar as relações privadas, criando uma esfera elementar da dignidade humana.

A formação dos direitos humanos se confunde com a própria história da humanidade, sendo certo que tais direitos não configuram uma pauta fixa e estanque, definida num único momento da história. Consubstanciam um catálogo aberto, ao qual se acrescem valores que a sociedade reputa importantes no decorrer de sua evolução. Refletem, nas palavras de Flávia Piovesan, "um construído axiológico, a partir de um espaço simbólico de luta e ação social".

Dentro desse catálogo encontra-se o acesso à justiça, que assegura a todo aquele que se sentir violado em um direito possa buscar uma solução perante o Poder

2 PIOVESAN, Flávia. Declaração Universal dos Direitos Humanos: desafios e perspectivas. Instituto de Hermenêutica Jurídica, Belo Horizonte, n. 7, p. 11-37, 2009. No mesmo sentido: LAFER, Celso. Prefácio. In: PIOVESAN, Flávia. Direitos Humanos e Justiça internacional. São Paulo: Saraiva, 2006, p. XXII. 
Judiciário. Tal é a sua importância que o acesso à justiça tornou-se uma garantia judicial contida no art. $8^{\circ}$ e 25 da Convenção Americana de Direitos Humanos.

Por garantir o respeito a todos os outros direitos humanos, o acesso à justiça ganhou relevância para o fortalecimento do sistema internacional de proteção aos Direitos Humanos. Esse fortalecimento despontou da reação das barbáries cometidas durante a Segunda Guerra Mundial, momento em que se verificou a necessidade de transcender os limites dos sistemas jurídicos internos para assegurar a proteção efetiva dos direitos humanos. Foi desse contexto que surgiu o Projeto de Florença.

\subsection{O Projeto de Florença e os obstáculos veri- ficados}

A obra "Access to Justice: the worldwide movement to make rights effective", publicada por Mauro Cappelletti e Bryant Garth em meados da década de 70 do século passado na Europa, foi fruto dos estudos promovidos à frente do Projeto de Florença. Tal Projeto ocupou-se com pesquisas na Itália, França, Espanha, Portugal, EUA entre outros países, visando diagnosticar as causas da ineficiência na prestação da justiça. Os resultados foram compilados em relatórios, que deram origem ao livro tão conhecido e importante para vários países.

Inicialmente, Mauro Cappelletti e Bryan Garth esclarecem que a problemática necessita ser encarada de forma multidisciplinar pela própria natureza dos obstáculos encontrados pelos estudiosos, que transpunham o âmbito exclusivo do Direito ${ }^{4}$.

Os autores empregaram a expressão "acesso à justiça" em dois sentidos. Num primeiro sentido, a expressão foi utilizada para retratar o acesso do cidadão ao Poder Judiciário. Num segundo sentido, retratou uma resposta Estatal vocacionada a surtir efeitos concretos individual e socialmente justos, que foi denominada de "acesso efetivo".

Segundo Mauro Cappelletti e Bryan Garth, o conceito de acesso à justiça não ficou inerte às influências

3 Tradução livre do título: "Acesso à Justiça: o movimento mundial de efetivação dos direitos".

4 CAPPELLETTI, Mauro; GARTH, Bryant. Acesso à justiça. Trad. e rev. Ellen Gracie Northfleet. Porto Alegre: Sergio Antonio Fabris Editor, 1988, p. 9

5 CAPPELLETTI, Mauro; GARTH, Bryant. Acesso à justiça. Trad. e rev. Ellen Gracie Northfleet. Porto Alegre: Sergio Antonio Fabris Editor, 1988, p. 10. dos regimes políticos e econômicos 6 . Os procedimentos adotados pelos Estados Liberais burgueses dos séculos dezoito e dezenove refletiram o ideal do liberalismo econômico e político, que, em suma, apregoava a ausência de interferência estatal na esfera social. Nesse período, o Estado permaneceu passivo ${ }^{7}$. Ao influxo disso, o acesso à justiça ganhou contornos de acesso ao Judiciário, uma noção eminentemente formal.

O serviço judiciário sempre exigiu altos custos. No modelo do laissez-faire, a justiça, assim como outros bens, só podia ser obtida por aqueles que pudessem enfrentar seus custos; aqueles que não pudessem fazê-lo eram considerados os únicos responsáveis por sua sorte ${ }^{8}$. Em suma, "afastar a 'pobreza no sentido legal' - a incapacidade que muitas pessoas têm de utilizar plenamente a justiça e suas instituições - não era preocupação do Estado", asseveram Mauro Cappelletti e Bryan Garth.

Nesse modelo, concluem Mauro Cappelletti e Bryan Garth, o estudo acerca do "acesso à justiça” era exegético, dogmático e indiferente aos problemas reais do foro, a exemplo da exclusão da população menos abastada dos serviços judiciários, bem como do aumento populacional que desencadeou uma demanda por interesses coletivos, a demandar uma atuação positiva do Estado para assegurar o gozo de todos os direitos sociais básicos, tais como saúde, trabalho, segurança, educação etc.

Diante desse cenário de desamparo social, exsurgiu a necessidade de interferência estatal para regulamentar novos direitos subjetivos, de índole transindividual, tendo como protagonistas os consumidores e o meio ambiente, por exemplo. Esse fenômeno evidenciou a transição do regime do laissez-faire para o welfare state.

6 CAPPELLETTI, Mauro; GARTH, Bryant. Acesso à justiça. Trad. e rev. Ellen Gracie Northfleet. Porto Alegre: Sergio Antonio Fabris Editor, 1988, p. 10.

7 Sobre as características dos modelos liberal (econômico e político) e dos demais modelos, conferir: GRAU, Eros Roberto. $A$ Ordem Econômica na Constituição de 1988. 11ª ed, São Paulo: Malheiros editores, 2006. Sobre os reflexos, no direito processual, da transição entre os modelos de Estado liberal e do Estado social, conferir excelente dissertação de mestrado: TEIXEIRA, Ludmila Ferreira. Acesso à justiça qualitativo. 2011. 183 f. Dissertação (mestrado). Programa de Pós-Graduação da Faculdade de Direito do Sul de Minas, Pouso Alegre, 2011.

8 CAPPELLETTI, Mauro; GARTH, Bryant. Acesso à justiça. Trad. e rev. Ellen Gracie Northfleet. Porto Alegre: Sergio Antonio Fabris Editor, 1988, p. 9.

9 CAPPELLETTI, Mauro; GARTH, Bryant. Acesso à justiça. Trad. e rev. Ellen Gracie Northfleet. Porto Alegre: Sergio Antonio Fabris Editor, 1988, p. 9. 
A partir desse diagnóstico, Mauro Cappelletti e Bryan Garth apontaram alguns obstáculos que se mostraram impedientes ao acesso efetivo ${ }^{10}$ :

a) custas judiciais, que de maneira geral são bem dispendiosas e provocava o afastamento da população, principalmente a economicamente menos favorecida, dos serviços jurisdicionais, algo que é agravado em alguns sistemas jurídicos pelo ônus da sucumbência, que é do vencido;

b) reflexo dos altos custos judiciais prejudica as pequenas causas, aonde mais se observa a desproporcionalidade entre o custo e o serviço judicial;

c) tempo, que tem por efeito aumentar os custos e pressionar os economicamente fracos a abandonar suas causas ou aceitar acordos por valores ínfimos;

d) possibilidades financeiras das partes. Algumas espécies de litigantes gozam de vantagens estratégicas, ligadas ao fator econômico, pois litigar é dispendioso e quem possui melhor situação financeira tem mais condições não só de propor uma ação como também de se defender e aguardar a resposta estatal. Aliado a isso, uma melhor situação financeira permite acesso à educação, informação, meio e status social, o que reflete a facilidade de compreensão do problema e da sua solução, dispensando, na maioria das vezes, a necessidade de procurar o Judiciário para resolver a questão;

e) "problemas especiais dos interesses difusos" que, em razão da sua natureza, ou ninguém que pertence ao grupo tem o direito de corrigir a lesão a um interesse coletivo, ou o prêmio para qualquer indivíduo buscar essa correção é suficientemente desestimulante para induzi-lo a procurar o serviço judicial.

Em suma, um serviço jurisdicional caro e ineficiente foi o retrato extraído pelos estudos do Projeto de Florença.

\subsection{Respostas apresentadas pelos estudos do Projeto de Florença}

Identificados os problemas que afetavam o acesso à justiça, a partir de 1965 os estudos voltaram-se para as

10 Nesta parte da obra, os autores afirmaram que a efetividade perfeita é algo utópico, mas que a preocupação da pesquisa era saber até onde avançar na direção do objetivo utópico. Sem embargo, entendemos que não há efetividade perfeita pela própria natureza evolutiva da sociedade, que tem a capacidade de se reconstruir ou de se remodelar em razão ou para enfrentar os seus problemas. soluções dessas barreiras, recebendo o nome de "ondas renovatórias".

A primeira onda frisou a necessidade de criação da assistência judiciária gratuita, que se preocupou com os pobres em razão de ser a classe excluída dos serviços judiciários por não apresentar condições de arcar com o alto custo desses serviços, nem de contratar um advogado ${ }^{11}$.

A segunda onda renovatória enfrentou o problema de representação dos interesses difusos ou interesses coletivos ou grupais. A concepção tradicional de processo civil não deixava espaço para a efetiva proteção dos direitos difusos. $\mathrm{O}$ tratamento legislativo ao processo judicial era individual por influência do Estado liberal que singularizava as partes e restringia a legitimidade por meio de institutos inadequados ao atendimento dos interesses difusos. Assim, era necessária a adequação legislativa ${ }^{12}$.

A terceira onda renovatória, denominada de acesso à justiça efetivo, centra sua atenção no conjunto geral de instituições, pessoas e procedimentos utilizados para processar e até mesmo prevenir litígios. Os novos direitos surgidos na sociedade moderna exigem novos mecanismos procedimentais que os tornem exequíveis. Esse enfoque induz a reflexão sobre a necessidade de ampla variedade de reformas, tais como alteração dos procedimentos, a fim de ajustá-los à complexidade das demandas, mudanças na estrutura dos tribunais e a criação de novos foros com o fito de aproximar o Judiciário da sociedade em busca da efetividade dos direitos ${ }^{13}$.

As semelhanças dos problemas analisados em diversos países e as soluções propostas implicaram a ampla ressonância dos estudos do Projeto de Florença.

\section{DAS ONDAS RENOVATÓRIAS AO ACESSO À JUSTIÇA QUALITATIVO - QUARTA ONDA RENOVATÓRIA?}

A implementação das medidas propostas pelo Projeto de Florença contribuiu significativamente, diminuin-

11 CAPPELLETTI, Mauro; GARTH, Bryant. Acesso à justiça. Trad. e rev. Ellen Gracie Northfleet. Porto Alegre: Sergio Antonio Fabris Editor, 1988, p. 31-48.

12 CAPPELLETTI, Mauro; GARTH, Bryant. Acesso à justiça. Trad. e rev. Ellen Gracie Northfleet. Porto Alegre: Sergio Antonio Fabris Editor, 1988, p. 49-66.

13 CAPPELLETTI, Mauro; GARTH, Bryant. Acesso à justiça. Trad. e rev. Ellen Gracie Northfleet. Porto Alegre: Sergio Antonio Fabris Editor, 1988, p. 67-73. 
do o abismo existente entre Poder Judiciário e população, sobretudo a menos favorecida economicamente. Entretanto, toda a problematização levantada por Mauro Cappelletti e Bryan Garth serviu bem aos moldes traçados pelo paradigma do Estado social.

Ao lado da importância dessas propostas, Dierle Nunes salienta que o movimento do Projeto de Florença surgiu no momento histórico em que a crise do Welfare state estava implementada pela incapacidade do Estado provedor cumprir suas promessas. E completa

\begin{abstract}
"No entanto, em face do exaurimento da perspectiva materializante do Welfare states, que pressupunha Estados com atribuiçôes funcionais tentaculares (assistencialista populista, em alguns exemplos) e que reduгia a autonomia dos cidadãos (pública e privada) ao mero exercicio do papel de cliente, com um efeito desmotivador de participação, vem se buscando opções para sua superação que não representem tão-somente o resgate de perspectivas liberais, mas a busca de perspectivas tensionais entre as argumentações tratadas até o momento."14
\end{abstract}

Sem desprezar todo o avanço do Projeto de Florença, esse estudo apresentou-se limitado em seus objetivos. Em 1970, os problemas que norteavam o acesso à justiça estavam ligados à questão econômica, direta ou indiretamente. Isso ficou ainda mais evidente com o declínio do Welfare state, que pressupunha a atribuição de funções assistencialistas e populistas ao Estado, reduzindo o campo de liberdade do cidadão e, por conseguinte, a livre iniciativa.

A superação do Welfare state e o advento de um terceiro paradigma, calcado numa concepção procedimental de Estado Democrático de Direito, como relatado por Marcelo Cattoni no trecho abaixo destacado, anunciou a necessidade de se repensar novas propostas para o problema do acesso à justiça:

\footnotetext{
"Com a crise do paradigma jurídico de bem-estar social e mesmo com as tentativas empreendidas pela dogmática jurídica, sobretudo germânica, de escapar da alternativa paradigma liberal' ou 'paradigma social', inclusive procurando estabelecer conexões mais ou menos 'bíbridas' entre eles, fomentou-se uma compreensão reflexiva do Direito, assim como a necessidade de se problematizar 'modelos sociais' que estariam inscritos no próprio Direito. Segundo Habermas, sua intenção, com a interpretação que vem desenvolvendo do Direito e da politica à luz da Teoria do Discurso, é, em face disso, a de 'dar contornos nitidos a um terceiro paradigma do Direito, que recapitule em si os outros dois. Parto de que o que mais se ajusta aos sistemas jurídicos que a fins do século XX vigem nas democracias de massas, articuladas em termos de Estado Social, é uma compreensão procedimental do Direito." 15
}

14 NUNES, Dierle José Coelho. Processo Jurisdicional Democrático: uma análise crítica das reformas processuais. Curitiba: Juruá, 2008, p. 135.

15 CATTONI DE OLIVEIRA, Marcelo. Teoria discursiva da ar-
Não se desconhece a contribuição trazida pela teoria discursiva de Habermas, bem evidenciada por Marcelo Cattoni, que apregoa uma leitura procedimental do Direito e da Democracia, seu referencial. A teoria discursiva é portadora de um "olhar" crítico multidisciplinar, que imprescinde da ampliação do diálogo social e interdisciplinar. Isso implica um esforço conjunto no sentido de se repensar o "acesso à Justiça", por promover a desejada ampliação do campo de participação social, a conferir uma investigação mais profícua dos reais entraves que ainda afligem os diversos segmentos sociais, e, consequentemente, a legitimar as decisões jurisdicionais ${ }^{16}$.

Aliada a isso, a globalização, fenômeno que se fez notar principalmente após a queda do Muro de Berlim, trouxe ao novo cenário social questões complexas diversas das jurídicas e econômicas, que reconhecidamente não foram objeto dos estudos do Projeto de Florença.

Essa perspectiva teórica e procedimental trouxe um avanço teórico que permitiu compreender o vazio deixado pela percepção quantitativa empregada pelo Projeto de Florença, que ignorou o aspecto qualitativo por adotar um ideal formalista de acesso à justiça, além de não desenvolver, no âmbito de suas propostas, as ideias democráticas para equalizar os problemas de representatividade.

Essas falhas ficaram evidentes com o surgimento de diversos estudos, que analisaram a problemática sob outras perspectivas. Em monografia que aborda a problemática do acesso à justiça no sistema inglês, Kim Economides explicita que, nos anos 60, um importante estudo desenvolvido nos Estados Unidos por Carlin e Howard identificou quatro estágios cruciais pelos quais os cidadãos têm de passar antes de ingressarem nos tribunais, sendo eles:

\footnotetext{
“1) a consciência, consubstanciada no reconbecimento pelo indivíduo de que determinado problema é um problema jurídico; 2) a vontade de deflagrar a ação judicial para solucioná-lo; 3) a procura de um advogado; e 4) a sua contratação efetiva"'17.
}

gumentação jurídica de aplicação e garantia processual jurisdicional dos direitos fundamentais. In: __ (coord.). Jurisdição e hermenêutica constitucional. Belo Horizonte: Mandamentos, 2004, p. 204.

16 CATTONI DE OLIVEIRA, Marcelo. Teoria discursiva da argumentação jurídica de aplicação e garantia processual jurisdicional dos direitos fundamentais. In: _ (coord.). Jurisdição e hermenêutica constitucional. Belo Horizonte: Mandamentos, 2004, p. 200.

17 J. Carlin \& J. Howard, Legal representation and class justice. Apud ECONOMIDES, Kim. Lendo as ondas do "movimento de acesso à justiça”: Epistemologia versus metodologia? In: PANDOLFI, Dulce, [et al]. (orgs). Cidadania, justiça e violência. Rio de Janeiro: Ed. 
O mesmo estudo demonstrou que os ricos nos Estados Unidos frequentemente optavam pela não utilização do Judiciário, resolvendo suas celeumas por meios privados ou informais ${ }^{18}$. Esse estudo apontou que as questões determinantes para o acionamento do Poder Judiciário transcendem as perspectivas econômicas. Um exemplo era a distância territorial, muito comum em países com extenso território, barreira que não integrou o objeto de estudo do Projeto de Florença.

A problemática envolvendo "acesso à justiça" também foi analisada sob o ângulo da administração da justiça. Destaca-se, nessa perspectiva, o estudo do sociólogo Boaventura de Sousa Santos ${ }^{19}$, que acrescentou o obstáculo social, compreendido como distância institucional entre governo e sociedade que se agrava com o questionamento da representatividade desse Poder, bem como o obstáculo cultural, caracterizado pelo temor de represálias e o medo que o cidadão sente em relação aos advogados e ao sistema judiciário ${ }^{20}$.

Fundação Getulio Vargas, 1999, p. 65. Disponível em: <www.cpdoc. fgv.br>. Acesso em: 19 jun. 2013.

18 ECONOMIDES, Kim. Lendo as ondas do "movimento de acesso à justiça”: Epistemologia versus metodologia? In: PANDOLFI, Dulce, [et al]. (orgs). Cidadania, justiça e violência. Rio de Janeiro: Ed. Fundação Getulio Vargas, 1999, p. 65. Disponível em: <www.cpdoc.fgv.br>. Acesso em: 19 jun. 2013.

19 SANTOS, Boaventura de Sousa. Introdução à sociologia da administração da justiça. Revista de Processo, São Paulo, n. 37, p. 121-129, jan./mar. 1985.

20 Exemplo da dificuldade cultural é o caso dos índios na Bolívia. Em 2009, a nova Constituição da Bolívia criou uma estrutura chamada de plurinacional, onde 36 etnias são reconhecidas como nações que, juntas, compõem o Estado Plurinacional da Bolívia. O próprio Tribunal Constitucional passou a ter uma composição mista, que representa as nações indígenas, assim como outras estruturas estatais.

Ainda que a nova Constituição já previsse a existência da Justiça Indígena Campesina, bem como sua coexistência com a Justiça Ordinária, o Tribunal Constitucional Plurinacional, em decisão inédita, trouxe um novo entendimento quanto a dimensão da atuação dessa justiça ancestral, hoje reconhecida pelo estado. O Tribunal, ao decidir uma questão de competência, utilizou como critérios informações culturais e antropológicas, com base em dados estatísticos e estudos realizados pela Unidade de Descolonização do Tribunal Constitucional Plurinacional, que, por meio de nota técnica, demonstra a origem étnica e formação cultural da população de Poroma. Além de dirimir conflito de competência entre a Justiça Comum e a Justiça Indígena Campesina por critérios culturais antropológicos, estabeleceu a coexistência de bases jurídicas distintas, de cada nação indígena e a ordinária, onde não há hierarquia entre elas, para em conjunto formar um modelo de jurisdição multifacetado que respeita a formação histórica de cada povo e ao mesmo tempo estabelece limites, tendo em vista os direitos humanos, tratados internacionais e garantias constitucionais. Notícia completa disponível em http://www2.stf.jus.br/portalStfInternacional/cms/destaquesNewsletter.php?sigla $=$ newsletterPortalInternaci onalDestaques\&idConteudo $=241307$, acessada em 11.07.2013.)
A abertura multidisciplinar revelou a insuficiência das medidas apregoadas pelo Projeto de Florença e a necessidade de se introduzir a análise qualitativa na abordagem do tema.

\subsection{Uma quarta onda renovatória?}

A necessidade de uma nova abordagem, desta feita qualitativa, sobre o acesso à justiça, foi sentida pelos diversos ramos da ciência social. O tratamento multidisciplinar da problemática "acesso à justiça” produziu um relevante ganho teórico, sobretudo pela participação da filosofia e da sociologia, a ponto de se afirmar a existência de uma quarta onda renovatória: o acesso dos operadores do direito à justiça.

A afirmação de uma nova onda renovatória advém das experiências extraídas do foro, principalmente com advogados, que constataram que o trabalho próximo da Justiça "cegava" a profissão jurídica em relação a concepções mais profundas de justiça (interna ou social) e, consequentemente, fazem com que a profissão ignore a relação entre justiça civil e justiça cívica. Essa corrente avança a pesquisa sobre o campo ético e político da administração da justiça, indicando importantes e novos desafios tanto no tocante à responsabilidade profissional como também no tocante ao ensino jurídico.

Segundo essas orientações, o problema atual não é simplesmente medir o acesso dos cidadãos à justiça, mas, antes, descortinar novas perspectivas na definição do termo justiça. A proposta passa a ser uma mudança importante de foco: da preocupação das questões metodológicas para as epistemológicas ${ }^{21}$. Assim:

\footnotetext{
"São duas as preocupações e os focos de análise da quarta onda: um é relativo ao acesso à educação jurídica; o outro, mais difficil, refere-se à questão de como garantir que, uma vez ingressado na carreira, tanto advogados quanto juízes bem representem a justiça. Este tema levanta, por sua vez, questões éticas referentes às responsabilidades mais amplas da participação das faculdades de direito e dos organismos profissionais não apenas no controle da admissão às carreiras jurídicas, mas também na definição de padrões minimos de profissionalização. Estes assuntos estão presentes na maioria dos sistemas legais modernos, todos lutando com a conciliação de tensões entre a manutenção da qualidade da justiça e de sen acesso,22.
}

21 ECONOMIDES, Kim. Lendo as ondas do "movimento de acesso à justiça": Epistemologia versus metodologia? In: PANDOLFI, Dulce, [et al]. (orgs). Cidadania, justiça e violência. Rio de Janeiro: Ed. Fundação Getulio Vargas, 1999, p. 72. Disponível em: <www.cpdpc.fgv.br>. Acesso em: 19 jun. 2013.

22 ECONOMIDES, Kim. Lendo as ondas do "movimento de acesso 
Fácil identificar que o primeiro tema refere-se ao acesso à educação jurídica. A preocupação do autor citado parte dos seguintes questionamentos: quem pode se qualificar como advogado ou juiz? Quem tem acesso às faculdades de direito? ${ }^{23}$ As faculdades são, invariavelmente, a porta de acesso às carreiras jurídicas, tornando-se imprescindível identificar e entender quem tem acesso ao ensino superior e em que bases.

Outra pergunta colocada por Kim Economides questiona se os governos, os organismos profissionais e os advogados precisam esforçar-se para promover positivamente o acesso à profissão legal de mulheres, minorias em desvantagem e outros grupos que sejam social ou historicamente excluídos? A pergunta é pertinente, pois a mudança de perspectiva, de olhar sobre o conceito de justiça passa pela inclusão de novos atores, tornando o ambiente mais plural ${ }^{24}$.

O segundo tema é mais complexo, referindo-se à questão de como garantir que, uma vez dentro da carreira, tanto advogados quanto juízes tenham acesso à justiça. A abordagem perpassa "por questôes éticas referentes as responsabilidades da participação das faculdades de direito e dos organismos profissionais não apenas no controle da admissão às carreiras jurídicas, mas também na definição de padrões minimos de profissionalização' ${ }^{\prime 25}$.

Relata Kim Economides que vem desenvolvendo estudos comparativos do ensino da ética legal visando a analisar mais profundamente estes dilemas éticos. Afirma que esses estudos também permitem uma melhor compreensão do papel e das responsabilidades das faculdades de direito na formação do caráter profissional dos advogados. A partir das suas observações, explicita

à justiça”: epistemologia versus metodologia? In: PANDOLFI, Dulce, [et al]. (orgs). Cidadania, justiça e violência. Rio de Janeiro: Ed. Fundação Getulio Vargas, 1999, p. 74. Disponível em: <www.cpdpc. fgv.br>. Acesso em: 19 jun. 2013.

23 ECONOMIDES, Kim. Lendo as ondas do "movimento de acesso à justiça”: epistemologia versus metodologia? In: PANDOLFI, Dulce, [et al]. (orgs). Cidadania, justiça e violência. Rio de Janeiro: Ed. Fundação Getulio Vargas, 1999, p. 74. Disponível em: <www.cpdpc. fgv.br>. Acesso em: 19 jun. 2013.

24 ECONOMIDES, Kim. Lendo as ondas do "movimento de acesso à justica": epistemologia versus metodologia? In: PANDOLFI, Dulce, [et al]. (orgs). Cidadania, justiça e violência. Rio de Janeiro: Ed. Fundação Getulio Vargas, 1999, p. 75. Disponível em: <www.cpdpc. fgv.br>. Acesso em: 19 jun. 2013.

25 ECONOMIDES, Kim. Lendo as ondas do "movimento de acesso à justiça”: epistemologia versus metodologia? In: PANDOLFI, Dulce, [et al]. (orgs). Cidadania, justiça e violência. Rio de Janeiro: Ed. Fundação Getulio Vargas, 1999, p. 75. Disponível em: <www.cpdpc. fgv.br>. Acesso em: 19 jun. 2013. que o ensino do direito transmite a percepção de que a justiça é uma utopia distante, um ideal inatingível ${ }^{26}$; e os advogados, ao invés de merecerem a fé, a confiança e o respeito do público, são vistos com desconfiança por que primordialmente motivados pela busca do lucro e não pelo seu compromisso com a justiça ${ }^{27}$.

Propõe, em resposta a essas questões, um exame cultural cruzado da dimensão macro, relativa à distribuição do recurso à lei, e da dimensão micro, atinente à responsabilidade profissional. Nesse sentido, tece críticas acerca dos Códigos de Ética dos profissionais que se silenciam sobre estes valores, preferindo enfocar o controle da conduta profissional e não a erradicação da injustiça ${ }^{28}$.

Explicitadas as premissas da quarta onda renovatória, esse novo olhar é desafiante porque retrata algumas deficiências internas do Poder Judiciário e dos operadores do direito.

\section{NOVO OLHAR SOBRE O ACESSO À JUSTIÇA - O QUestionário da Comissão Interamericana de Direitos Humanos}

$\mathrm{O}$ acesso à justiça de qualidade, por ser um direito humano consagrado na Convenção Americana de Direitos Humanos, também tem sido uma preocupação da Comissão e da Corte Interamericanas. A Comissão Interamericana de Direitos Humanos, órgão que tem como função precípua, de acordo com o art. 44 da Convenção Americana de Direitos Humanos, receber denúncias de violação a direitos humanos e investigá-las, funciona, em outras palavras, como um grande "filtro" para onde são encaminhadas todas as denúncias, que são analisadas e, se preenchidos os requisitos do art. 46 da Convenção, são submetidas ao julgamento da Corte Interamericana, órgão de função jurisdicional. Nesse

\footnotetext{
26 Talvez por influência do Projeto de Florença.

27 ECONOMIDES, Kim. Lendo as ondas do "movimento de acesso à justiça": epistemologia versus metodologia? In: PANDOLFI, Dulce, [et al]. (orgs). Cidadania, justiça e violência. Rio de Janeiro: Ed. Fundação Getulio Vargas, 1999, p. 75. Disponível em: <www.cpdpc. fgv.br>. Acesso em: 19 jun. 2013.

28 ECONOMIDES, Kim. Lendo as ondas do "movimento de acesso à justiça”: epistemologia versus metodologia? In: PANDOLFI, Dulce, [et al]. (orgs). Cidadania, justiça e violência. Rio de Janeiro: Ed. Fundação Getulio Vargas, 1999, p. 75. Disponível em: <www.cpdpc. fgv.br>. Acesso em: 19 jun. 2013.
} 
mister, a Comissão solicita informações ao governo denunciado e às autoridades envolvidas. Assim, por canalizar as reclamações, tem a capacidade de identificar o problema.

A Comissão, em razão das inúmeras denúncias recebidas, percebendo as falhas de determinados sistemas internos dos Estados-membros, elaborou um questionário para compreensão prática dos fatores que interferem no acesso à justiça, que será abordado a seguir.

\subsection{0 propósito do questionário e a preocupa- ção da Comissão com o acesso à justiça de qua- lidade}

Por iniciativa da sua secretaria executiva, a Comissão formulou um questionário com dezesseis perguntas cujas respostas ficariam a cargo dos Estados e da sociedade civil e deveriam ser entregues até o dia 15 de Março de 2013. Dele se extrai a preocupação da Comissão quanto a possíveis fatores que possam afetar a imparcialidade e a independência administrativa e financeira dos membros do Poder Judiciário, do Ministério Público e da Defensoria Pública.

Essa pesquisa também investiga o modo de ingresso e de permanência nas carreiras dos membros, as políticas de segurança adotadas pelo Estado para assegurar o exercício pleno e independente dessas funções.

O propósito do questionário está estampado nas considerações iniciais do documento:

\footnotetext{
"Este questionário foi preparado pela Secretaria Executiva da CIDH para coletar informações relevantes dos Estados e da sociedade civil para a elaboração de um relatório sobre a situação dos operadores de justiça nas Américas com o objetivo de identificar os problemas por eles enfrentados e promover a plena utilização de padrões internacionais que sirvam de guia aos Estados nas linhas de ação a serem seguidas para garantir sua independência e imparcialidade ${ }^{\prime 29}$.
}

Perguntas que indagam sobre a existência de eventuais critérios para garantir a adequada representatividade da sociedade nos cargos de juízes, promotores e defensores públicos e que questionam a duração estabelecida para os cargos, sugerem que a Comissão adota uma concepção qualitativa de acesso à justiça, preocupada não só com a representatividade da população e com os contornos democráticos de acesso aos cargos

29 Questionário disponível em: http://www.oas.org/pt/ cidh/docs/pdf/OperadoresJusticia2013PO.pdf, acessado em 06/07/2013. do Poder Judiciário, mas também com a qualidade do serviço jurisdicional prestado, na mesma esteira das propostas da quarta onda renovatória.

A segurança da integridade física e a corrupção dos integrantes das carreiras da Magistratura, do Ministério Público e da Defensoria Pública foram preocupações visíveis no questionário, fenômenos que inegavelmente abalam a imparcialidade e a independência funcional dos operadores.

A análise das denúncias admitidas pela Comissão e submetidas à Corte Interamericana revelou que inúmeros $\operatorname{casos}^{30}$ tratavam de violações às garantias institucionais dos operadores da justiça. Os mais emblemáticos foram relatados a seguir.

\subsubsection{Garantias da Magistratura, do Ministério Público e da Defensoria Pública}

A análise dos principais textos normativos de direitos humanos permite afirmar que, malgrado abordarem as garantias das carreiras dos operadores da justiça deixam a cargo dos Estados-membros a regulamentação minuciosa dessa matéria. Destaca-se, como exemplo, o artigo X da Declaração Universal dos Direitos Humanos que assegura a toda pessoa o direito de ser julgada por um tribunal independente e imparcial, norma que se repete no art. $8^{\circ}$ da Convenção Americana de Direitos Humanos.

Em regra, os sistemas jurídicos internos dos Estados arrolam, como garantias, a independência funcional, a autonomia administrativa e financeira, a inamovibilidade e a irredutibilidade de vencimentos ${ }^{31}$.

Por independência funcional entende-se que o operador da justiça não se encontra vinculado a nenhum po-

30 Casos que também foram admitidos pela Comissão e encaminhados para a análise e julgamento da Corte: CIDH, Petição 691-04: Caso Omar Francisco Canales Ciliezar versus Estado de Honduras. Informe 71/2010; CIDH, Petição 1119-02: Caso Aura de Las Mercedes Pacheco Briceño y Balbina Francisca Rodríguez Pacheco versus Venezuela, Informe n ${ }^{\circ}$ 20/2012; CIDH, Petição 70-08: Caso Pedro César Marcano versus Venezuela. Informe n ${ }^{\circ}$ 10/2013; CIDH, Petição 266-03: Caso Lilia Alejandra Garcia Andrade y otros versus México. Informe no 59/2012; CIDH, Petição 911-98: Caso Héctor Fidel Cordero Bernal versus Peru. Informe no 112/2011; CIDH, Petição 13-04: Caso Ricardo Vaca Andrade versus Ecuador. Informe no 172/2011.

31 Não se mencionou a vitaliciedade, garantia comum aos cargos do Ministério Público e da Magistratura no Brasil, porque, de acordo com o questionário, ela não deveria existir nos sistemas democráticos por não permitir a renovação representativa desejada. 
der público ou autoridade pública no cumprimento de suas funções institucionais. As autonomias administrativa e financeira permitem que o órgão estatal não esteja vinculado, administrativamente, a nenhum outro órgão, além de conferir a capacidade de gestão e de elaboração do seu próprio orçamento. A inamovibilidade permite que o membro não seja removido ou afastado, por vontade de terceiros ou estratagema institucional, da apreciação de um determinado caso. Por fim, a irredutibilidade de vencimentos afasta a possibilidade de qualquer decisão legislativa com o intuito de diminuir os subsídios pagos aos exercentes de determinada função ${ }^{32}$.

A importância do respeito às garantias funcionais dos operadores da justiça não é preocupação nova. Inusitado é o olhar sobre o "funcionamento da engrenagem chamada Justiça”. Será que a aludida engrenagem funciona adequadamente?

A análise das diversas denúncias ${ }^{33}$ admitidas pela Comissão Interamericana identificou falhas nessa "engrenagem", isto é, os casos tratavam de violações às garantias funcionais dos operadores da justiça.

No tocante à Magistratura, os casos apreciados pela Comissão envolveram, em sua maioria, questionamentos sobre a violação à imparcialidade, ausência de identificação dos julgadores, corrupção, uma atuação irregular do órgão de fiscalização dos juízes e destituição do cargo sem observância do procedimento adequado.

O caso mais emblemático foi o de Adan Guillermo Lopes Lone e outros ${ }^{34}$, admitido pela Comissão em 31.03.2011. De acordo com as informações veiculadas no informe $n^{\circ} 70 / 11$ da Comissão, em 6 de julho de 2010 a Comissão recebeu uma denúncia da Associa-

32 Preferiu-se o termo "função" ao termo "poder" porque, de acordo com a clássica doutrina da tripartição do poder estatal, o Poder do Estado é único, o que se divide são as funções, que são atribuídas a órgãos estatais estruturalmente distintos mas institucionalmente ligados.

33 Casos que também foram admitidos pela Comissão e encaminhados para a análise e julgamento da Corte: CIDH, Petição 691-04: Caso Omar Francisco Canales Ciliezar versus Estado de Honduras. Informe 71/2010; CIDH, Petição 1119-02: Caso Aura de Las Mercedes Pacheco Briceño y Balbina Francisca Rodríguez. Pacheco versus Venezuela, Informe no 20/2012; CIDH, Petição 70-08: Caso Pedro César Marcano versus Venezuela. Informe no 10/2013; CIDH, Petição 266-03: Caso Lilia Alejandra Garcia Andrade y otros versus México. Informe n 59/2012; CIDH, Petição 911-98: Caso Héctor Fidel Cordero Bernal versus Peru. Informe no 112/2011; CIDH, Petição 13-04: Caso Ricardo Vaca Andrade versus Ecuador. Informe $\mathrm{n}^{\circ}$ 172/2011.

34 CIDH, Petição 975-10: Caso Adan Guillermo Lopez Lone y otros versus Honduras, Informe no $70 / 11$. ção dos Juízes para a Democracia (AJD) e do Centro pela Justiça e do Direito Internacional (CEJIL) contra o Estado de Honduras ao fundamento de que o Tribunal Superior de Justiça de Honduras teria exonerado, de forma arbitrária, ilegal e politicamente motivada, os juízes Guillermo López Lone, Luis Alonso Chévez de la Rocha, Maldonado Ramón Enrique Barrios e Tirza del Carmen Flores Lanza, que alegam violação dos artigos 8 (garantias judiciais), 13 (liberdade de pensamento e de expressão), 15 (liberdade de reunião), 16 (liberdade de associação) e 25 (Proteção Judicial) da Convenção Americana sobre Direitos Humanos.

O caso mencionado despertou a atenção por envolver um pedido das Associações de Magistrados sobre violação das garantias de mais de um magistrado, o que denota a forte ingerência do governo de Honduras no Poder Judiciário e a importância das entidades de classe para os operadores da justiça. Ademais, a narrativa dos fatos aponta, como questão principal, a violação às garantias institucionais. Em vários outros casos apreciados pela Comissão essa temática não constitui o ponto nodal do debate, sendo analisada apenas de forma periférica.

Outro expressivo exemplo foi o caso Rogelio Morales Martinez versus México ${ }^{35}$, admitido em 17 de julho de 2012. Nesse caso, a Comissão consignou que o acesso à justiça, em que pese ter sido de certo modo observado, não se deu de forma eficaz, porque a vítima era indígena e não dominava o idioma utilizado pelos operadores da justiça, prejudicando a participação da vítima em todo o procedimento e seu direito de tentar influenciar a decisão do magistrado competente, afetando a qualidade do acesso à justiça.

No que toca às garantias do Ministério Público, não houve muitos casos apreciados. Todavia, um caso, em especial, cujo relato dos fatos denunciou a inoperância do Ministério Público do Estado do Rio de Janeiro Brasil, o que, por si, consubstancia uma violação à garantia da independência funcional. Segundo o informe, em 26 de dezembro de 2001, a Comissão Interamericana recebeu uma petição apresentada por Ivanilde Telacio dos Santos, Rafaela Telacio dos Santos, Rosana Tibuci Jacob e Fagner Gomes dos Santos, pelo Núcleo de Estudos Negros (NEN) e pelo Centro de Justiça Global (CJG) na qual se alega a violação, por parte da Repúbli-

35 CIDH, Petição 728-04: Caso Rogelio Morales Martinez versus México, Informe no 67/2012. 
ca Federativa do Brasil dos artigos 4, 5, 8, 24, 25 e 1(1) da Convenção Americana sobre Direitos Humanos, em prejuízo de Wallace de Almeida, vítima, ao fundamento de que policiais militares assassinaram a presumida vítima e que a investigação policial ainda estava inconclusa e sem a apresentação da denúncia pelo Ministério Público à justiça. Por fim, requereram que se recomende ao Estado do Brasil que investigue, julgue e puna os responsáveis pelo crime praticado, que as vítimas sejam indenizadas e que se tomem medidas para evitar ações policiais violentas como a denunciada ${ }^{36}$.

Também não há casos encontrados que relatem a violação das garantias institucionais dos membros da Defensoria Pública. Todavia, do relato de alguns casos é possível extrair a inoperância de seus membros, seja por questões de ineficiência do serviço, seja por ingerência de membros de outros Poderes, que traduz ofensa às garantias funcionais da Defensoria Pública. Foi o que ocorreu no caso Hildebrando Silva de Freitas versus Brasil. Segundo o informe no 146/11 $1^{37}$, em 3 de abril de 2007, a Comissão recebeu uma petição submetida pela Sociedade Paraense de Defesa dos Direitos Humanos (SDDH) e o Centro pela Justiça e o Direito Internacional (CEJIL) na qual se alegava que a responsabilidade internacional do Brasil pela arbitrária detenção, tortura e violação da integridade pessoal de Hildebrando Silva de Freitas, em Belém, Estado do Pará. Segundo os peticionários, a suposta vítima foi arbitrariamente detida por policiais, em 15 de novembro de 1997, por desacato, crime tipificado no Código Penal Brasileiro, além de não ter sido imediatamente informado sobre as acusações que lhe eram imputadas. Os peticionários também alegaram que, desde o momento da detenção inicial e durante toda a prisão processual, a suposta vítima esteve sujeita à violência policial, o que configura tortura e violação da integridade pessoal. Os peticionários acrescentaram que, apesar das queixas apresentadas pela suposta vítima às autoridades competentes, não foi instaurado inquérito oficial e, até hoje, o Estado não puniu as violações alegadas. $\mathrm{O}$ relato revela a inoperância da Defensoria Pública, que deveria ter atuado em defesa do peticionário.

De outro lado, o estudo das denúncias apreciadas pela Comissão Interamericana revelou que a maioria

36 CIDH, Petição 12.440: Caso Wallace de Almeida versus Brasil. Informe $n^{\circ}$ 26/2009.

37 CIDH, Petição 405-07: Caso Hildebrando Silva de Freitas versus Brasil. Informe $\mathrm{n}^{\circ}$ 146/2011. dos casos problematizavam a duração do processo, decorrente sobretudo da inoperância dos operadores da justiça. Todavia, verificou-se que os motivos dessa inoperância estavam ligados a fatores que afligiam as garantias funcionais dos operadores, revelando uma relação direta entre acesso à justiça e duração razoável do processo e o seu caráter excludente, que torna a morosidade um dos maiores e mais nefastos obstáculos ao acesso, ainda a ser superado ${ }^{38}$.

Dessas constatações fica nítida a preocupação da Comissão com o respeito às garantias institucionais dos operadores da justiça na América. Esta preocupação é legítima e destaca a necessidade de um acesso à justiça qualitativo.

\section{Considerações finais}

Partindo da noção de acesso à justiça como direito humano, que assegura a todo aquele que se sentir violado em um direito possa buscar uma solução perante o Poder Judiciário, procurou-se abordar o contexto inicial da preocupação com o acesso à justiça que motivou o Projeto de Florença, até o contexto atual, tentando justificar a reanálise do tema.

Em um primeiro momento, caracterizou-se o Projeto de Florença, apontando seus ideais e objetivos. Todavia, a análise retrospectiva permitiu concluir que esse movimento surgiu no momento histórico em que a crise do Welfare state estava implementada pela incapacidade do Estado provedor cumprir suas promessas, servindo aos ideais do paradigma social.

Com a afirmação do paradigma democrático e o surgimento de novos desafios trazidos pela globalização, o novo cenário social questões complexas diversas das jurídicas e econômicas, que reconhecidamente não foram objeto dos estudos do Projeto de Florença, justificou uma releitura do tema.

Essas observações permitiram compreender o vazio deixado pela percepção quantitativa empregada pelo Projeto de Florença, que ignorou o aspecto qualitativo por adotar um ideal formalista de acesso à justiça.

38 Sobre o tema, conferir TEIXEIRA, Ludmila Ferreira. Acesso à justiça qualitativo. 2011. Dissertação (mestrado). Programa de PósGraduação da Faculdade de Direito do Sul de Minas, Pouso Alegre, 2011, p. 123-129. 
O tratamento multidisciplinar da problemática "acesso à justiça", sobretudo com a participação da filosofia e da sociologia, foi crucial para eclodir um novo olhar sobre a problemática, podendo-se afirmar a existência de uma quarta onda renovatória: o acesso dos operadores do direito à justiça.

A afirmação de uma nova onda renovatória adveio das experiências extraídas do foro, principalmente com advogados, que concluiu que o trabalho próximo da Justiça "cegava" a profissão jurídica em relação a concepções mais profundas de justiça (interna ou social) e, consequentemente, fazem com que a profissão ignore a relação entre justiça civil e justiça cívica, denotando uma pesquisa focada no campo ético e político da administração da justiça.

Segundo essas orientações, o problema atual não é simplesmente medir o acesso dos cidadãos à justiça. Propõe-se uma mudança importante de foco: da preocupação das questões metodológicas para as epistemológicas.

A Comissão Interamericana, em razão das inúmeras denúncias recebidas, percebeu as falhas de determinados sistemas estatais e elaborou um questionário para compreensão prática dos fatores que interferem no acesso à justiça qualitativo e estudo de possíveis soluções.

Perguntas que indagam sobre a existência de eventuais critérios para garantir a adequada representatividade da sociedade nos cargos de juízes, promotores e defensores públicos e que questionam a duração estabelecida para os cargos, permitem concluir que houve, por parte da Comissão, a adoção de uma concepção qualitativa de acesso à justiça, preocupada com a qualidade do serviço jurisdicional prestado, o que se assemelha com as ponderações levantadas pelos defensores da quarta onda renovatória.

Destarte, a compreensão do questionário possibilitou aferir algumas orientações que demonstram a contribuição da Comissão Interamericana de Direitos Humanos para melhorar o acesso à justiça. São elas:

1) Prevenção de ingerências de outros poderes públicos no trabalho de juízes, promotores e defensores públicos;

2) O processo e os critérios aplicáveis na seleção e nomeação de juízes, promotores e defensores públicos, não sujeitos a período de prova, confirmação posterior ou ratificação de alguma autoridade;
3) A representatividade da sociedade nos cargos de juízes, promotores e defensores públicos, inclusive com a inserção de critérios como gênero, raça ou etnia para favorecer a adequada representação da população;

4) Mandatos temporalmente delimitados;

5) A participação do Poder Judiciário, do Ministério Público e da Defensoria Pública na elaboração e do debate sobre seus respectivos orçamentos;

6) Instituição de procedimentos e critérios objetivos para promoções ou transferências de graus na carreira, embasados na eficiência;

7) Processos de suspensão ou destituição de cargos com hipóteses bem definidas, assegurados todos os meios de defesa e eliminadas as imunidades.

8) Um bom ambiente de trabalho, com estrutura, segurança, recursos logísticos e técnicos, inclusive com pessoal de apoio;

9) Políticas públicas que promovam a segurança dos membros;

10) Políticas públicas efetivas de combate à corrupção dos operadores da justiça;

11) Cursos de capacitação periodicamente promovidos pelas instituições, inclusive como requisitos para permanência e ascensão no cargo;

12) Ombudsman para coletar denúncias de vítimas das violações de direitos humanos.

De fato, para a prestação de um serviço judiciário de qualidade e preocupado com a eficiência, imprescindível o respeito às garantias que permitam aos operadores da justiça o exercício imparcial e independente das suas funções.

Registre-se, por fim, o lapso da Comissão que não contemplou, em seu questionário, os advogados, operadores de notória relevância para um acesso à justiça de qualidade. 


\section{REFERÊNCIAS}

ALEXANDRINO, Marcelo. PAULO. Vicente. Direito Constitucional Descomplicado. Rio de Janeiro: Impetus, 2007.

ANNONI, Danielle. Direitos bumanos \& acesso à justiça no direito internacional: responsabilidade internacional do estado. Curitiba: Juruá, 2003.

CAPPELLETTT, Mauro; GARTH, Bryant. Acesso à justiça. Trad. e rev. Ellen Gracie Northfleet. Porto Alegre: Sergio Antonio Fabris Editor, 1988.

CATTONI DE OLIVEIRA, Marcelo. Teoria discursiva da argumentação jurídica de aplicação e garantia processual jurisdicional dos direitos fundamentais. In: (coord.).

Jurisdição e hermenêutica constitucional. Belo Horizonte: Mandamentos, p. 189-225, 2004.

CIDH, Petição 911-98: Caso Héctor Fidel Cordero Bernal versus Peru. Informe no 112/2011.

CIDH, Petição 1119-02: Caso Aura de Las Mercedes Pacheco Briceño y Balbina Francisca Rodríguez. Pacheco versus Venezuela, Informe $\mathrm{n}^{\circ}$ 20/2012.

CIDH, Petição 266-03: Caso Lilia Alejandra Garcia Andrade y otros versus México. Informe no 59/2012.

CIDH, Petição 13-04: Caso Ricardo Vaca Andrade versus Ecuador. Informe no 172/2011.

CIDH, Petição 691-04: Caso Omar Francisco Canales Ciliezar versus Estado de Honduras. Informe 71/2010.

CIDH, Petição 728-04: Caso Rogelio Morales Martinezv versus México, Informe no 67/2012.

CIDH, Petição 405-07: Caso Hildebrando Silva de Freitas versus Brasil. Informe no 146/2011.

CIDH, Petição 70-08: Caso Pedro César Marcano versus Venezuela. Informe no 10/2013.

CIDH, Petição 12440-09: Caso Wallace de Almeida versus Brasil. Informe no 26/2009.

CIDH, Petição 975-10: Caso Adan Guillermo Lopę Lone y Otros versus Honduras, Informe $\mathrm{n}^{\circ} 70 / 11$.

DIAS, Ronaldo Brêtas de Carvalho. Processo Constitucional e Estado democrático de Direito. $2^{\mathrm{a}}$ Edição. Belo Horizonte: Del Rey, 2012.

ECONOMIDES, Kim. Lendo as ondas do "movimento de acesso à justiça”: Epistemologia versus metodologia? In: PAN-
DOLFI, Dulce, [et al]. (orgs). Cidadania, justiça e violência. Rio de Janeiro: Ed. Fundação Getulio Vargas, 1999, p. 61-76. Disponível em: <www.cpdoc.fgv. br>. Acesso em: 19 jun. 2013.

FERNANDES, Bernardo Gonçalves. Curso de Direito Constitucional. 3.ed. Rio de Janeiro: Lumen Juris, 2011.

GRAU, Eros Roberto. A Ordem Econômica na Constituição de 1988. 11 a ed, São Paulo: Malheiros editores, 2006.

IPEA. Mapa da Defensoria Pública no Brasil. 1 ed. Brasília. 2013. Disponível em: < http://www.ipea.gov. br/sites/images/downloads/mapa_da_defensoria_publica_no_brasil_impresso.pdf $>$. Acesso em: 09 jul. 2013.

JAYME, Fernando G. Direitos Humanos e sua efetivação pela Corte Interamericana dos Direitos Humanos. Belo Horizonte: Del Rey, 2005.

JUNQUEIRA, Eliane Botelho. Acesso à Justiça: um olhar retrospectivo. Revista Estudos Históricos, n. 18 - Justiça e Cidadania. São Paulo: CPDOC/FGV, p. 1-15, 1996-2.

MIGUEL, Daniel Oitaven Pamponet; BOSON, Erik Palácio. A Defensoria Pública e o reconhecimento dos direitos bumanos: uma leitura democrático-procedimental da cidadania como exigência deôntico-teológica. Revista da Faculdade Mineira de Direito, Belo Horizonte, v.15, n.30 , p.4563, Obs. on line, jul. 2012.

NUNES, Dierle José Coelho. Processo Jurisdicional Democrático: uma análise crítica das reformas processuais. Curitiba: Juruá, 2008.

OLIVEIRA, Márcio Luís (org.). O Sistema Interamericano de Proteção dos Direitos Humanos: interface com o direito constitucional contemporâneo. Belo Horizonte: Del Rey, 2007.

PEREIRA, Antônio Celso Alves. Acesso a justiça e direitos bumanos: o problema no Brasil. Revista da Faculdade de Direito: [Rio de Janeiro], Rio de Janeiro, n.2 , p.123-134, jan. 1994.

PIOVESAN, Flávia. Declaração Universal dos Direitos Humanos: desafios e perspectivas. Revista do Instituto de Hermenêutica Jurídica, Belo Horizonte, n. 7, p. 1137, 2009.

PIOVESAN, Flávia. Direitos Humanos e Justiça internacional. São Paulo: Saraiva, 2006.

PORTELA, Paulo Henrique Gonçalves. Direito Internacional Público e Privado. 3a ed, Salvador: Juspodivm, 2009. 
ROCHA, Paulo Osório Gomes. Concretização de direitos fundamentais na perpectiva jurídica-constitucional da defensoria pública: um caminho ainda a ser trilhado. Revista de Direito Constitucional e Internacional, São Paulo , v.15, n.60 , p.184-206, jul./set 2007.

ROBERT, Cinthia; SÉGUIN, Elida. Direitos bumanos, acesso à justiça: um olhar da defensoria pública. Rio de Janeiro: Forense, 2000.

SANTOS, Boaventura de Sousa. Introdução à sociologia da administração da justiça. Revista de Processo, São Paulo, n. 37, p. 121-129, jan./mar. 1985.

TEIXEIRA, Ludmila Ferreira. Acesso à justiça qualitativo. 2011. 183 f. Dissertação (mestrado). Programa de Pós-
Graduação da Faculdade de Direito do Sul de Minas, Pouso Alegre, 2011.

WAGNER JUNIOR, Luiz Guilherme da Costa et al. Poder judiciário e carreiras jurídicas. Belo Horizonte: Del Rey, 2006.

\section{Sites PESquisados}

www.presidencia.gov.br

www.stj.jus.br

www.cidh.org.br 
Para publicar na Revista de Direito Internacional, acesse o endereço eletrônico www.rdi.uniceub.br ou www.brazilianjournal.org.

Observe as normas de publicação, para facilitar e agilizar o trabalho de edição. 